\title{
Feedback Analysis and Prevention \& Control Strategy of the Real Causes of the Gallery Cracks in Super-High Arch Dam
}

\author{
Yaosheng TAN ${ }^{\mathrm{a}, 1}$, Chunfeng LIU ${ }^{\mathrm{a}}$, Youzhi LIU ${ }^{\mathrm{b}}$ and Jingtao LI ${ }^{\mathrm{b}}$ \\ ${ }^{a}$ China Three Gorges Projects Development Co. Ltd Sichuan Chengdu, China \\ ${ }^{\mathrm{b}}$ China Institute of Water Conservancy and Hydropower Research Beijing, China
}

\begin{abstract}
Gallery cracks occur commonly in concrete dams, but their cracking mechanism has yet to be effectively revealed. In this paper, the actual temperature, stress change history and cracking process of a gallery area were uncovered, based on the safety monitoring data of cracks in a super-high arch dam. In addition, the basic development and change laws, as well as the corresponding cracking mechanism, were analyzed, and the real causes and influential factors of cracks at the site were revealed, which will provide a reference for the prevention of cracks in similar projects in the future.
\end{abstract}

Keywords. High arch dam, crack in gallery, temperature control and crack prevention, real temperature stress, mesoscopic analysis

\section{Introduction}

Gallery cracks are common in concrete dams, and have yet to be effectively resolved. There are many examples of cracks in outlets or galleries of existing concrete dams in countries outside of China. Some cracks gradually develop and expand; these are extremely harmful, and even affect the normal operation of the dam. For example, there are cracks in both the upper inspection gallery and lower drainage gallery of No. 35 dam block of the Dworshak concrete dam in the United States, which have developed into a vertical cleavage crack along the upstream surface. In addition, the Norfork gravity dam and Richard B Russel Dam also have longitudinal cracks at the flood releasing bottom outlet. Furthermore, the Revelstoke gravity dam in Canada suffered serious cracks over a period of less than six months. Similarly, many concrete dams in numerous countries have cracks in their outlets, such as the former Soviet Union's Mamakan slotted gravity dam and Morikawa River massive-head dam in Japan [1-5].

1 Yaosheng Tan, China Three Gorges Projects Development Co. Ltd Sichuan Chengdu, China, E-mail: 1244292229@qq.com. 
In recent years, several super-high arch dams established in China also have gallery cracks [6-8]. If these gallery cracks only exist in the shallow area, then in general they will not affect the safety of the dam. However, if the cracks are deep, then they may cross the break-stop steel bars, and even penetrate the upstream dam surface [9-12]. Under such conditions, the structural safety of the dam may be at risk. Therefore, gallery cracks require special attention. For super-high arch dams, due to their high overall stress level and three-dimensional statically indeterminate structure, gallery cracks are more likely to exacerbate the local stress state of the dam, which may affect the overall stress state and bearing capacity, which in turn may have adverse effects under the induction of unfavorable factors. Therefore, although the restricted fissure design is generally taken for the stress of the gallery, it is still a meaningful task if reasonable optimization measures could be adopted before crack occurrence to reduce the stress level in the gallery area as much as possible, so as to control the total stress within the allowable range, and reduce or even avoid cracks. This is also a consensus reached by industry workers. Many scholars have also carried out related research on this issue.

ZHANG et al. [6] discussed the causes of cracks in super-high arch dams during the construction period, as well as the temperature control and crack prevention measures, and proposed that the control of temporal and spatial temperature gradients should be given ample attention during the construction of super-high arch dams. Academician ZHU Bofang [10] proposed a strategy and method for building an arch dam that will never crack, by controlling the temperature difference and carrying out thermal insulation measures on both the upstream and downstream dam surfaces. This method focused on the implementation of the overall crack prevention measures of the dam, and did not propose any specific advice on the prevention of gallery cracks. CHEN et al. [11] adopted the FEM numerical simulation to study the stress of the gallery under the action of the gravity and temperature stress of the arch dam during the construction period, and held that the roof arch of the gallery is more greatly affected by the gravity than by the temperature stress. In said paper, the focus is on analyzing the stress of the gallery after the second-stage cooling of the arch dam has been completed. JIN et al. [12] simulated the stress of the gallery under different influential factors during the construction period, and held that greater attention should be given to the stress of the steep slope dam block and ambient temperature in the gallery, both of which have a great influence on the stress of the roof arch and floor of the gallery. MA et al. [7] adopted the microseism monitoring technique to analyze the occurrence and derivation of gallery cracks, which can only be qualitatively analyzed, thus this cannot be used to establish a quantitative relationship between stress and cracks. In general, most research in the currently available literature is mainly based on post analysis, namely the causes of the crack are estimated by simulation following crack occurrence. The feedback and quantitative analyses regarding the temperature and stress of crack area of the gallery based on actual safety monitoring data are rare in existing literature. Most of the analyses are qualitative, and the accuracy of quantitative analysis is insufficient, thus these can only play a relatively small role in guiding on-site crack prevention. In addition, in previous studies there is a lack of accurate description of the entire process of formation and evolution of gallery cracks in high arch dams. These studies do not distinguish the real causes of gallery cracks in different stages and types throughout the process of arch dam construction and water storage and the gravity of influence of each factor. This results in major safety hazards to the prevention of gallery cracks in arch dams, and hinders the realization of overall prevention and 
control of the risk of gallery cracking.

In the present paper, combined with the prototype observation experiment in the gallery area of a super-high arch dam, the actual temperature, stress change history and cracking process of the gallery roof area were revealed throughout the entire process. In addition, the finite element feedback simulation analysis was conducted to accurately reveal the causes and cracking mechanism of gallery cracks in dams, and to define the real causes and influential factors of on-site cracks. Based on this, in order to effectively reduce the stress in the gallery area at different stages of the construction process, and to reduce the risk of gallery cracking, a multi-factor sensitivity analysis was performed and specific strategies and controlling methods for the prevention of gallery cracks in super-high arch dams were proposed. This will provide a reference for the prevention of gallery cracks in similar projects, as well as the optimization and adjustment of future design schemes.

\section{Cracking Mechanism of Gallery Cracks}

The causes of gallery cracks in high arch dams mainly include the temperature stress and structural stress caused by weight. The local stress concentration area is formed in the roof arch and floor of gallery under the gravity load. Coupled with the superposition effect of temperature stress, cracks will occur after the stress exceeds the tensile strength of the concrete, which is generally caused by the superposition of two stresses. In addition, improper maintenance during the construction period may also result in shallow cracks, due to dry shrinkage. Due to the restricted fissure effect of steel bars surrounding the gallery, the gallery cracks are generally irregular. Typical gallery cracks in the roof and floor are shown in figure 1.

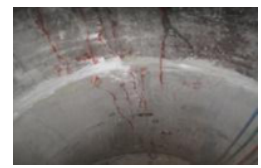

(a) Cracks in the roof

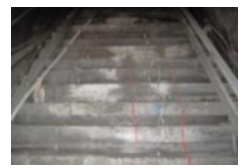

(b) Cracks in the floor

Figure 1. Typical cracks distribution in the gallery of a high arch dam.

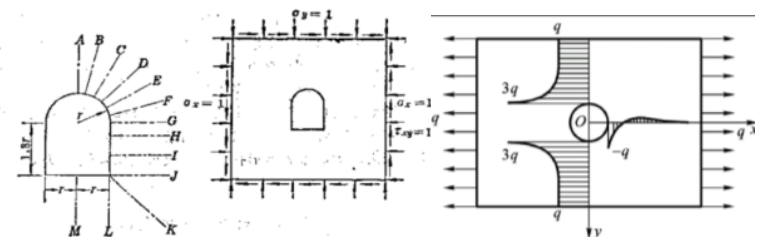

Figure 2. Photoelectric test diagram of the standard gallery [1].

The gallery area is prone to cracking, mainly due to the fact that the gallery structure will expand the stress effect under certain conditions. From the photoelectric test diagram of the standard gallery shown in figure 2 , when there are small holes in the elastic body, then the stress at the edge of the hole is much greater than that when no hole is present, and it is also much greater than the stress far away from the hole. Theoretically, when there is no hole in the dam, then the tensile stress of about $1 \mathrm{MPa}$ is generated along the river direction internally, and the tensile stress $\left(\sigma_{y}, \sigma_{x}, \tau_{x y}\right)$ 
occurring along the river direction on the floor of hole area (point A) will reach $3 \mathrm{MPa}$, with obvious stress concentration at the edge of the hole.

\section{Feedback Analysis of the Real Causes of the Gallery Cracks of Arch Dam}

\subsection{Analysis of Monitoring Data of Gallery}

A high arch dam in southwestern China has many galleries inside the dam body, including a grouting gallery, inspection gallery and drainage gallery. After the beginning of the project, in view of the problem of gallery cracking, simulation analysis was adopted to predict the risk of gallery cracking during the construction period of the dam, as shown in figure 3. According to the simulation calculation results, if the temperature control shown in Scheme I were to be adopted, then the risk of local cracking in the gallery of a steep slope dam block is very high. Only when the highest temperature shown in Scheme II, which does not exceed $23^{\circ} \mathrm{C}$, is taken, and the later thermostatic control inside the gallery is ensured, can the risk of cracking be controlled.
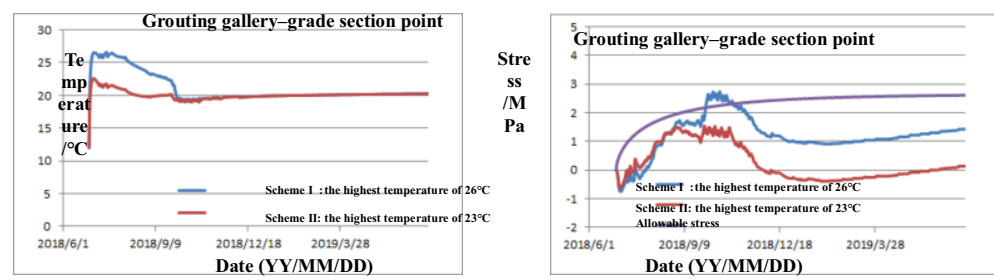

Figure 3. Typical curve of temperature and stress at typical points on the roof of gallery.

In view of the actual local climate conditions of the project and use of secondary aggregate grading concrete at this location, the amount of cementitious materials is abundant, which make it difficult to achieve the requirements shown in Scheme II and the risk of cracking high. Therefore, reinforcement meter and stress-strain gauge were embedded inside the dam at this location and in the gallery during construction, so as to track the actual temperature and stress status of the gallery area. The specific layout position is shown in figure 4. Among these, the reinforcement stress meter and strainmeter at No. 11 dam block are all arranged at a distance of $10 \mathrm{~cm}$ from the roof arch surface of the gallery, and are positioned at the same elevation as the outermost first layer of steel bars of the gallery.

Figure 5 shows the monitoring value of the monitoring instrument in the gallery area. It can be seen that the values of the reinforcement meter and gallery strainmeter of the reinforcement meter (No. R600-11-2 and R600-11-4) of the No. 11 dam block clearly show a sudden change and continued increase during the period of September 25,2018 to October 13, 2018. The increase amplitude exceeds $30 \mathrm{MPa}$ and $300 \mu \varepsilon$ in the short term, and this is completely consistent with the temperature change process. This gradual increase does not tend to decrease until the internal temperature of the gallery begins to rise in early February, 2019. The surface stress change in the surface gallery area is clearly closely related to the temperature change process. During the daily on-site inspection on October 13, 2018, shallow microscopic checks were observed on the roof of the gallery. The width of the crack was less than $0.1 \mathrm{~mm}$, the depth of the crack was $4-5 \mathrm{~cm}$, and none exceeded the first layer of break-stop steel 
bars. The actual crack direction is shown in figure 6. It is not difficult to see that the situation observed by the monitoring instrument is able to accurately reflect the development and change of stress and strain in the gallery area of the dam.

From a theoretical analysis perspective, when the tensile stress of the concrete on the roof arch of the gallery gradually approaches the tensile strength of the concrete, then the steel bars will gradually share greater tensile stress. In addition, when the surface stress of the gallery exceeds the tensile strength of the concrete, then the cracks are formed on the surface of the gallery. At that time, the stress in the gallery area will be redistributed, the steel bars in the gallery area will share more tensile stress, and the stress of the steel bars will suddenly increase. According to the monitoring data of the on-site steel bars shown in figure 5 , the actual situation is highly consistent with the theoretical analysis results.

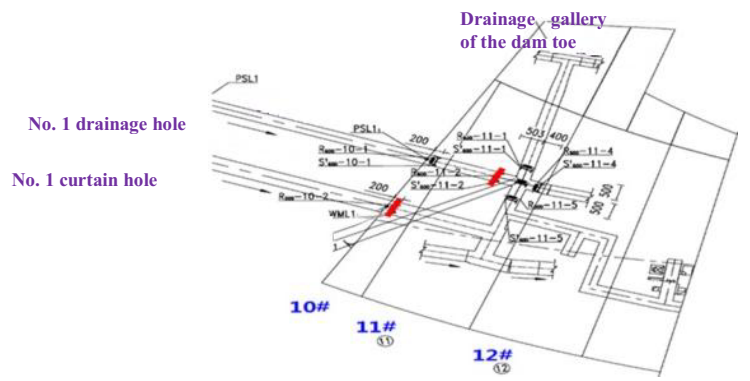

Figure 4. Layout of monitoring instruments for the top arch area of the dam block in the gallery area.

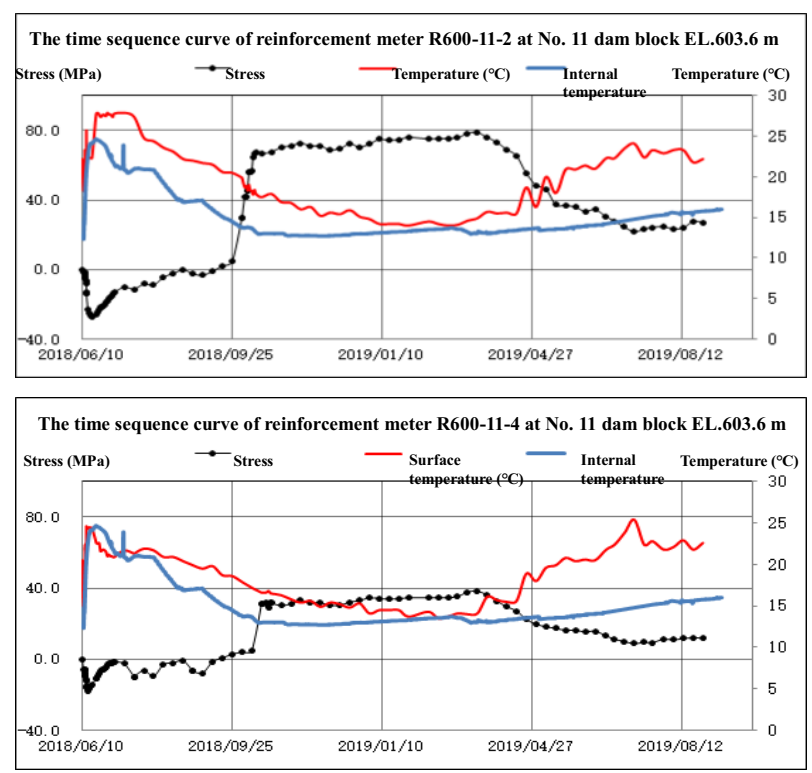

Figure 5. Monitoring data of temperature, stress and strainmeter at the roof arch of the gallery. 

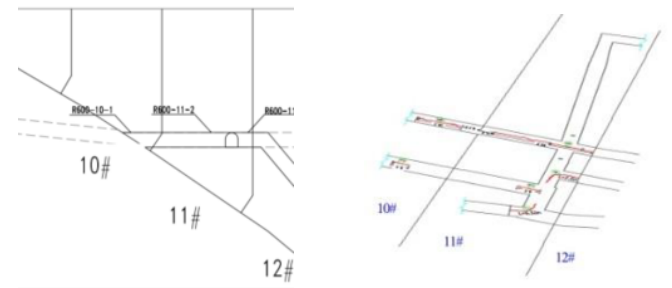

Figure 6. Plane distribution diagram of gallery cracks.

Elevation (m)
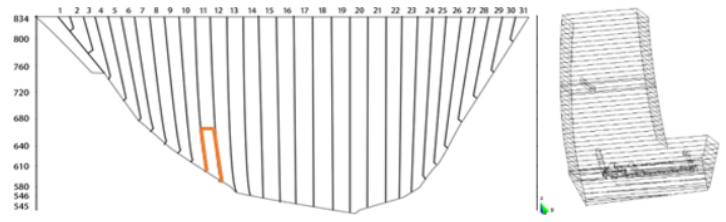

Figure 7. Computational model.

\subsection{Feedback Simulation and Analysis of the Causes of Cracks in the Gallery Area}

In order to thoroughly analyze the causes of gallery cracks, as well as to further verify the consistency between the on-site safety monitoring data and the previous simulation calculation results, a combined simulation calculation model was established, as shown in figure 7. The combined simulation calculation model of overall simulation and fine simulation of single dam block was built, which applies the temperature and force boundary of the overall simulation to both sides of a single dam block.

With the aid of the monitoring data obtained by the on-site thermometers arranged inside the dam and the gallery area, the temperature field in the gallery area of the dam was inverted. In particular, relying on the temperature of the reinforcement meter in the gallery surface, the temperature process of surface concrete in the gallery area was finely inverted. As shown in figure 8, the inversion values of the dam concrete in the pouring layer of the gallery area and temperature in the gallery area are completely consistent with the calculated value. This indicates that the temperature process obtained by inversion can represent the real temperature change process of the dam. Meanwhile, the superposition process of gravity load and the autogenous volume deformation load (from on-site monitoring data without stressmeter) were considered in the simulation calculation.

Figure 9 shows the comparison curve of the temperature, stress and strength curves of the gallery roof of No. 11 dam block. It can be seen that, since September 25, 2018, the stress exceeded the allowed stress which means the safety coefficient of the concrete on the surface of the gallery roof had fallen below 1.5; as required in the Code, the safety coefficient must be over 1.5. At this time, the internal temperature of the gallery area was $14.5^{\circ} \mathrm{C}$, which has not reached the design arch sealing temperature of $13^{\circ} \mathrm{C}$, and the temperature on the surface of the gallery roof was still approximately $18.7^{\circ} \mathrm{C}$. After this, as the overall temperature of the dam dropped to the arch sealing temperature, the stress reached the first highest point. Next, the later stress continued to increase with the further drop of the temperature on the surface of the gallery. In late February of 2019, the temperature reached its lowest point, and the stress reached another peak. 

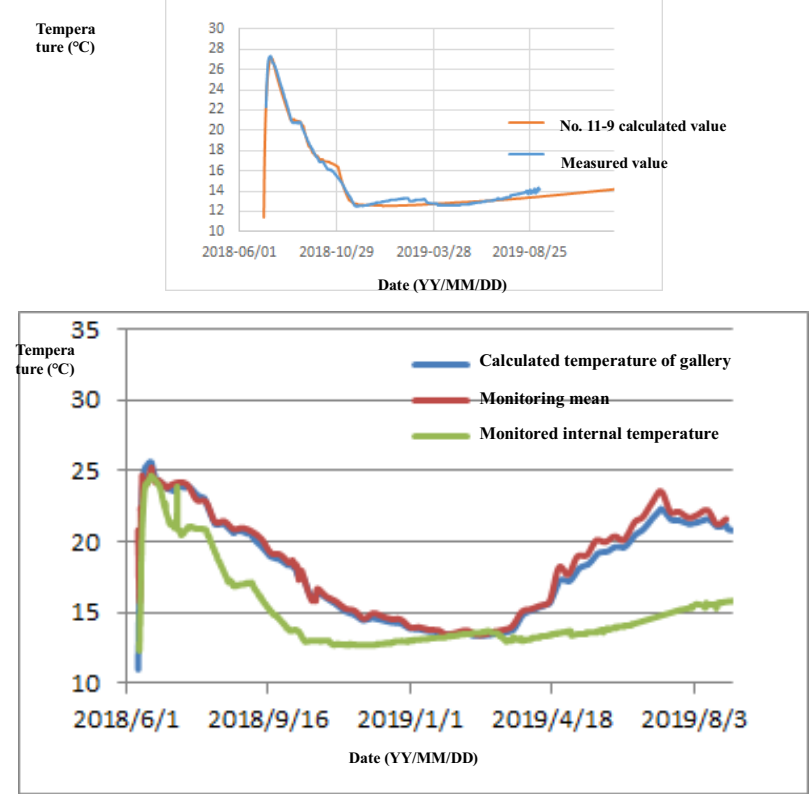

Figure 8. Comparison of measured temperature and monitored temperature at typical points around the gallery.

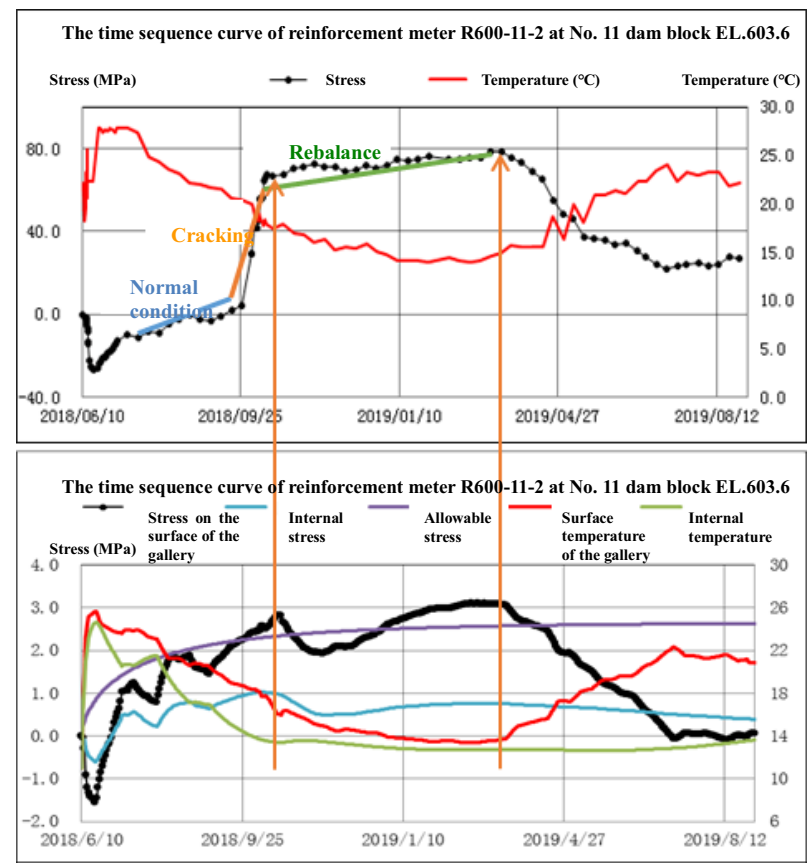

Figure 9. Comparison of measured temperature, stress and feedback simulation value of typical parts of the gallery.

It is not difficult to see that, when the surface safety coefficient of the gallery drops 
to about 1.5 , then the risk of cracking becomes very high. This is basically the same as the time when cracks are observed on-site. The change process of stress and safety coefficient is consistent with the change trend reflected by the monitoring value of on-site surface strainmeters and gallery reinforcement stress meter, thus indicating that the feedback simulation results can basically reflect the change law of the overall stress and safety status of the gallery area of the No. 11 dam block. Among them, the tensile stress generated by the overall and local temperature drop in the dam forms a concentration effect in gallery roof, which is the main cause of gallery cracks.

\section{Quantitative Analysis on Influential Factors and Prevention Measures of Gallery Cracks}

The above simulation results verify that the cause of the cracks is caused by the combined stress exceeding the standard. Due to the fact that this combined stress is the result of the combined effects of different influential factors, it is necessary to clarify the contribution of different influential factors to the stress of the gallery, so as to provide better ideas and directions for the prevention and control of gallery cracks. The main causes of gallery cracks in this project include three types of loads of temperature, gravity and autogenous volume deformation. The dry shrinkage load is not considered in this project, as the entire process of spray curing is carried out inside the gallery following the construction. Figure 10 shows the contribution of different loads to the stress of the gallery roof. It can be seen that the contributions of temperature, gravity and autogenous volume deformation are $1.55 \mathrm{MPa}, 0.33 \mathrm{MPa}$ and $0.55 \mathrm{MPa}$ at September 25, 2018 respectively. Clearly, at this stage, the temperature factor occupies a relatively large proportion. The main reason for this is that the gallery is in the strong foundation restraint area and is in the second-stage cooling, and the stress level in the gallery area is relatively large. Therefore, in this project the reduction of temperature stress is of primary importance from the perspective of gallery crack prevention.

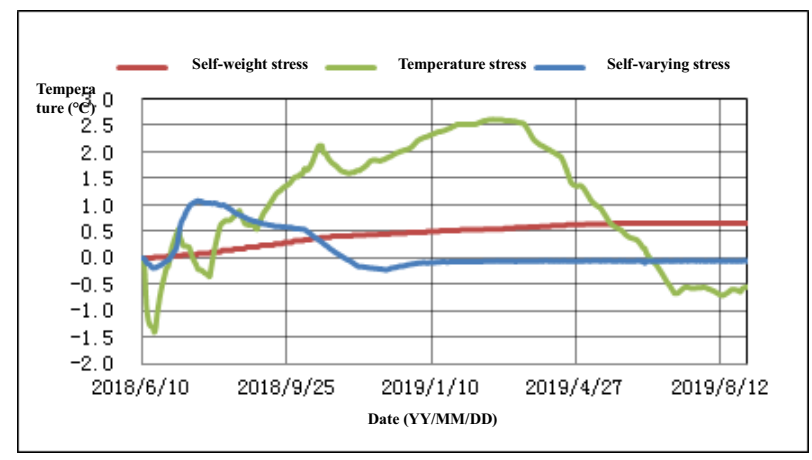

Figure 10. Comparison of stress curve of different influential factors.

\section{Conclusions and Suggestions}

Through the research of this paper, the main conclusions achieved are as follows:

(1) For the first time, the entire process of the occurrence and propagation of 
shallow gallery cracks was captured on the project site, and the causes and mechanism of the cracks were verified by means of numerical simulation.

(2) For shallow gallery cracks before the second-stage cooling during the construction period, the temperature stress was shown to have accounted for a relatively large proportion, while the gravity load accounted for a relatively small proportion. The gallery effect would expand the tensile stress on the surface of the gallery, which is one of the main causes of gallery cracks. Temperature stress remains the key factor which must be controlled.

(3) In order to reduce the risk of gallery cracking, in addition to lowering the highest temperature in the gallery area as a whole, the entrance and exit of the gallery must be closed as much as possible, so as to reduce the influence of outside temperature on the gallery. Meanwhile, the necessary maintenance is also beneficial to preventing shallow dry shrinkage cracks.

\section{References}

[1] Pan JZ. Holes and galleries in dam. Shanghai: Shanghai Scientific \& Technical Publishers; 1959 Sep; 365-370. (in Chinese)

[2] Zhu BF. Cleavage crack of gravity dam. Journal of Hydroelectric Engineering. 1997 Apr; 36(4): 85-97. (in Chinese)

[3] Bao RX. Hazards, causes and prevention of cracks in concrete dams. Water Resources and Hydropower Engineering. $1990 \mathrm{Jul}$; 35(7): 40-35. (in Chinese)

[4] Bruner WJ, Wu KH. Cracking of the revelstoke concrete gravity clam mass concrete. 15th International Congress on Large Dams, Lausanne, 1985 Jul; 2: 563-574.

[5] Peng KZ. Study on temperature control and crack prevention of concrete in grouting gallery of stone dam during construction period. Master thesis of North China University of Water Resources and Electric Power, 2016 May. (in Chinese)

[6] Zhang GX, Liu YZ, Liu Y, et al. Analysis on the causes of crack formation and the methods of temperature control and crack prevention during construction of super-high arch arms. Journal of Hydroelectric Engineering. 2010 May; 44(5): 45-51. (in Chinese)

[7] Ma K, Zhuang D Y, et al. Research on crack causes in the Dagangshan Hydropower Station high arch dam based on microseismic monitoring. Chinese Journal of Rock Mechanics and Engineering. 2018 Apr; 4(3): 1608-1617. (in Chinese)

[8] Chen Y, Zhang L, Yang BQ, et al. Geomechanical model test on dam stability and application to Jinping high arch dam. International Journal of Rock Mechanics and Mining Sciences. 2015 Jan; 76(1): $1-9$.

[9] Tang HJ, Zhang JH, Chen JF. Crack treatment on roller compacted concrete arch dam of Liubo Hydropower Station in Anhui Province. Water Resources and Hydropower Engineering. 2012 Jul; 43(7): 72-74. (in Chinese)

[10] Zhu BF. On the feasibility of building high quality arch dams without cracking and the relevant techniques. Journal of Hydraulic Engineering. 2006 Sep; 37(10): 1155-1162. (in Chinese)

[11] Chen PP, Zhang GX, Liu Y. Cause analysis of gallery cracks in roof arch of high arch dam. beijing society and theoretical and applied mechanics, Proceedings of the 19th Annual Conference of Beijing Society and Theoretical and Applied Mechanics. Beijing: Beijing Society and Theoretical and Applied Mechanics Press, 2013 Aug; p. 544-545. (in Chinese)

[12] Jin XX, Zhou QJ, ZHANG G X, et al. Analysis on factor of influence from real stress of gallery in concrete dam. Water Resources and Hydropower Engineering. 2018 Sep; 49(10): 33-38. (in Chinese) 